\title{
Composite zeolite beta catalysts for catalytic hydrocracking of plastic waste to liquid fuels
}

\author{
Dureem Munir ${ }^{1,2} \cdot$ Hassaan Amer $^{1} \cdot$ Rabya Aslam $^{1} \cdot$ Mohamed Bououdina $^{3} \cdot$ Muhammad Rashid Usman $^{1,4}$ (i)
}

Received: 22 January 2020 / Accepted: 6 April 2020 / Published online: 13 April 2020

(c) The Author(s) 2020

\begin{abstract}
The conversion of model waste plastic mixture into high-value liquid product was studied in the presence of hydrogen and composites of zeolite beta catalysts. For the sake of comparison, the conversion of actual waste plastic mixture and highdensity polyethylene was also carried out. The composite zeolite beta catalysts were synthesized using a range of silica-toalumina ratios, alkali concentrations, and hydrothermal treatment times. SEM, EDX, XRD, $\mathrm{N}_{2}$-BET, FTIR, and py-FTIR were used for the characterization of the catalysts. The catalytic experiments were conducted in a $500 \mathrm{ml}$ stirred batch reactor at $20 \mathrm{bar}$ initial cold $\mathrm{H}_{2}$ pressure and the temperature of the reaction was varied between 360 and $400{ }^{\circ} \mathrm{C}$. The two composite catalysts, $\mathrm{BC} 27$ and $\mathrm{BC} 48$, prepared without alkali pretreatment were found to be the most suitable catalysts. With $\mathrm{BC} 27$ and $\mathrm{BC} 48$ at $400{ }^{\circ} \mathrm{C}, 93.0 \mathrm{wt} \%$ conversion was obtained with actual plastic mixture and the liquid yield exceeded $68.0 \mathrm{wt} \%$. Experiments with the regenerated catalysts showed their performance comparable to the fresh catalysts.
\end{abstract}

Keywords Chemical recycling $\cdot$ Plastic conversion $\cdot$ Waste plastic $\cdot$ Zeolite beta $\cdot$ Composite catalyst

\section{Introduction}

Conventional methods used for the disposal of plastic wastes such as landfilling and incineration are not desirable from the environmental viewpoint. Landfilling ends in the accumulation of a large volume of plastic waste over an extended period of time [1, 2]. Not only is landfilling an environmental burden, but it also wastes the useful energy contents of the plastics [1,3-5]. Incineration, on the other hand, results in the emissions of toxic pollutants into the environment [3, 4, 6-9]. Chemical recycling of plastic wastes into functional products is perhaps the most preferred method of waste plastic management [10-13]. In one of the chemical recycling methods, the waste plastics are converted, in the

Muhammad Rashid Usman

mrashidusn@squ.edu.om

1 Institute of Chemical Engineering and Technology, University of the Punjab, Lahore, Pakistan

2 Faculty of Applied Science and Technology, Sheridan College, Brampton, Canada

3 Department of Physics, College of Science, University of Bahrain, Zallaq, Kingdom of Bahrain

4 Department of Petroleum and Chemical Engineering, Sultan Qaboos University, Muscat, Oman presence of hydrogen, into high-quality liquid fuels. The long-chain plastic molecules are transformed into smaller more useful products of gasoline and diesel range [5]. The efficiency of this hydroconversion or hydrocracking process is further enhanced by the use of a catalyst that considerably reduces the process reaction temperature, while increasing the selectivity of the products. In the literature, various catalytic materials are used for the hydrocracking of plastic materials. Several researchers employed zeolites including HZSM-5 [10, 14-21], HY [10, 22], and HUSY [23-25]. These zeolite catalysts showed quite favorable activity, but the product obtained comprised mostly gases pertaining to the microporous nature of these catalysts [26, 27]. The catalysts that contain mesopores such as Al-SBA-15 [28], Al-SBA-16 [25, 28, 29], and Al-MCM-41 [10] are also used in the literature though by only a few researchers. The mesoporous catalysts demonstrate excellent diffusion of heavier molecules and the product obtained consists of higher liquid contents. However, mesoporous catalysts show weak cracking ability due to their weak acidic nature [30, 31]. A micro-mesoporous composite catalyst is, therefore, considered to accommodate the advantages of each of the two microporous and mesoporous characters. The combination provides the initially cracked large polymer segments an easy access to the active sites of the catalyst and thereby

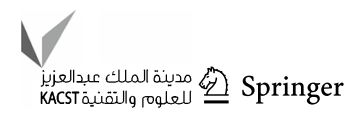


increases the activity of the microporous zeolite. Moreover, mesopores allow the large molecular weight molecules to reach in the gas phase as reaction product. A more liquid containing and more useful product is thus resulted. Composites of mesoporous catalysts with zeolite nanoseeds, for the plastic hydrocracking, are used by Munir and Usman [28, 29]. However, the results obtained over these catalysts were not satisfactory. Composites of zeolites can also be prepared by introducing mesoporosity in the preformed (previously synthesized) zeolites. This approach was used in our previous work for the synthesis of micro-mesoporous composites of commercial HUSY with SBA-16 [25]. The composites of USY catalysts showed promising results and demanded additional study over the composites of other zeolites.

In the present work, commercial zeolite beta (CP811C300) is used for the synthesis of micro-mesoporous composite catalysts. Zeolite beta is a large pore crystalline aluminosilicate material. Its highly acidic nature and distinct pore structure make it able to be applied in fluid catalytic cracking [32], hydroforming [33], etc. In the current study, zeolite beta and its in-house synthesized composite catalysts are used for the catalytic hydrocracking of model waste plastic mixture, HDPE, and actual waste plastic mixture. Additional experiments are performed for the evaluation of catalyst stability. To our knowledge, these types of catalysts have never been used for the catalytic hydrocracking of plastics.

\section{Experimental}

\section{Materials}

Commercial zeolite beta catalyst (CP811C300) was obtained from Zeolyst International. Both virgin and waste plastic materials were used for the cracking reactions. Virgin plastics such as high-density polyethylene (HDPE, $\rho=0.952 \mathrm{~g} /$ $\mathrm{cm}^{3}$ ), low-density polyethylene (LDPE, $\rho=0.918 \mathrm{~g} / \mathrm{cm}^{3}$, $\mathrm{MP}=100-125^{\circ} \mathrm{C}$ ), polypropylene (PP, MW $=250,000 \mathrm{~g} /$ mol, $\rho=0.9 \mathrm{~g} / \mathrm{cm}^{3}$ ), and polystyrene (PS, MW $=192,000 \mathrm{~g} /$ mol) were obtained from Sigma-Aldrich. Waste plastics such as HDPE (shampoo bottles washed, cleaned, and dried), LDPE (unused plastic bags used for shopping), PP (unused boxes used for takeaways), and PS (unused tea cups), all were procured from the local market.

\section{Catalyst preparation}

$8.28 \mathrm{~g}$ of a mixture of pluronic F-127 (Sigma-Aldrich) and pluronic P-123 Sigma-Aldrich) was added into $1 \mathrm{M} \mathrm{HCl}$ solution and the solution was stirred for $3 \mathrm{~h} .0 .1063 \mathrm{~g}$ of $\mathrm{NH}_{4} \mathrm{~F}$ ( $\geq 98.0 \%$ purity, Sigma-Aldrich) was then added into the solution. Separately, 1.5 M NaOH solution was prepared and $3.7 \mathrm{~g}$ of powdered zeolite beta (CP811C300, Zeolyst) was added to it and the solution was stirred for $1 \mathrm{~h}$ at $60{ }^{\circ} \mathrm{C}$. A third solution was prepared by adding $4.9 \mathrm{~g}$ of aluminumisopropoxide (AIP, $\geq 98.0 \%$ purity, Sigma-Aldrich) into $1 \mathrm{M}$ $\mathrm{HCl}$ solution. The resulting solution was stirred for $4 \mathrm{~h}$ at room temperature to have a homogeneous solution. The first two solutions were collected together and the produced solution was stirred continuously for $15 \mathrm{~min} .40 \mathrm{~g}$ of tetraethylorthosilicate (TEOS, 98.0\% purity, Sigma-Aldrich) was then added into this solution. The solution was again stirred for $4 \mathrm{~h}$ at $50{ }^{\circ} \mathrm{C}$. After that, the third mixture was poured into it and the final mixture was then continuously stirred for $24 \mathrm{~h}$. For the hydrothermal treatment, the mixture was charged into a stainless steel autoclave and crystallized at $110^{\circ} \mathrm{C}$ in an oven for $27 \mathrm{~h}$. The autoclave was lined with Teflon to avoid any interaction of the stainless steel with the mixture contents. Before transferring the mixture to the autoclave, the $\mathrm{pH}$ value of 4.0 was adjusted. Ammonia solution (33.0\% $\mathrm{NH}_{3}$, Riedel-de-Haën) was used to regulate the $\mathrm{pH}$ of the mixture. The final product was centrifuged while washing several times with doubly distilled water. The product was then dried in an oven for $20 \mathrm{~h}$ at $100{ }^{\circ} \mathrm{C}$ and later calcined in a muffle furnace for $5 \mathrm{~h}$ at $600{ }^{\circ} \mathrm{C}$, with a heating ramp of $2{ }^{\circ} \mathrm{C} / \mathrm{min}$. The synthesized catalyst had a sodium form. To achieve the proton form, the ion-exchange procedure was performed. This procedure was done by stirring the catalyst in $100 \mathrm{ml}$ of $3 \mathrm{M}$ ammonium acetate ( $\geq 98.0 \%$ purity, Sigma-Aldrich) solution at $60^{\circ} \mathrm{C}$, under vigorous stirring for $5 \mathrm{~h}$. The ammoniated catalyst was then filtered and washed with doubly distilled water. Later, it was dried in an oven at $100{ }^{\circ} \mathrm{C}$ for $12 \mathrm{~h}$. The catalyst was again calcined at $600{ }^{\circ} \mathrm{C}$ for $4 \mathrm{~h}$ in a muffle furnace. The final catalyst was called as BC11.1. The catalyst BC5.7 was synthesized using the same procedure, however, the TEOS/beta ratio was set as 5.7 (wt/ wt). BC0.7 and BC27 were synthesized with $0.7 \mathrm{M}$ and $0 \mathrm{M}$ $\mathrm{NaOH}$ (no sodium hydroxide), respectively, keeping all the other variables as constant. $\mathrm{BC} 48$ was produced from the same method as that of $\mathrm{BC} 27$, however, in this case, the duration of the hydrothermal treatment was $48 \mathrm{~h}$ in contrast to $27 \mathrm{~h}$ used for all the other catalysts.

\section{Catalyst characterization}

Field emission scanning electron microscope (Mira 3 TESCAN) was used for the SEM images. The catalyst samples were sputtered with carbon before taking their micrograph. The BET surface areas, pore size distributions, and nitrogen adsorption-desorption isotherms at $77.3 \mathrm{~K}$ were measured using Micromeritics TriStar II-3020. The catalyst samples were degassed at $200{ }^{\circ} \mathrm{C}$ for $2 \mathrm{~h}$ under vacuum using Micromeritics Smart Prep (Programmable Degas System), before the analysis. PANanalytical Empyrean diffractometer (Cu-K $\alpha$ X-ray radiations) with $0.013^{\circ}$ step size and $8.67 \mathrm{~s}$ step time was used for small-angle XRD patterns of the 
calcined catalysts. The $2 \theta$ range covered was $0.5^{\circ}-4^{\circ}$. PANalytical X'Pert diffractometer was used for wide-angle XRD that using the Ni-filtered $\mathrm{Cu}-\mathrm{K} \alpha$ radiation $(\lambda: 0.145 \mathrm{~nm})$ and with the scanning step of $0.02^{\circ}$ per step for the $2 \theta$ range of $6^{\circ}-90^{\circ}$. Infrared (IR) spectra of the catalysts were obtained using JASCO, FTIR-4100. In the FTIR analysis, pellets made out of $98 \%$ of $\mathrm{KBr}$ and $2 \%$ of catalyst sample were used. The $400-4000 \mathrm{~cm}^{-1}$ range was selected for the analysis. Py-FTIR (Pyridine, $\geq 99.0 \%$, Sigma-Aldrich) analysis was employed to observe the character of the acid sites. The same FTIR machine mentioned above was used for the PyFTIR and $1400-1700 \mathrm{~cm}^{-1}$ was set as the range of analysis.

\section{Catalytic experiments}

Catalytic hydrocracking of the model plastic mixture that consisted of $40 \mathrm{wt} \%$ HDPE $\left(\rho=0.952 \mathrm{~g} / \mathrm{cm}^{3}\right.$, SigmaAldrich), $10 \mathrm{wt} \%$ LDPE $\left(\rho=0.918 \mathrm{~g} / \mathrm{cm}^{3}, \mathrm{MP}=100-125^{\circ} \mathrm{C}\right.$, Sigma-Aldrich), $30 \mathrm{wt} \%$ PP $(\mathrm{MW}=250,000 \mathrm{~g} / \mathrm{mol}$, $\rho=0.9 \mathrm{~g} / \mathrm{cm}^{3}$ ), and $20 \mathrm{wt} \%$ PS (MW $=192,000 \mathrm{~g} / \mathrm{mol}$ ) was carried out for the evaluation of activity and selectivity of the synthesized catalysts. The experiments were performed in a $500 \mathrm{ml}$ high pressure stirred autoclave reactor (Parr Instrument Co.). A schematic diagram of the reactor is shown in Fig. 1. The details of the experimental setup can be found in Munir [34].

$10 \mathrm{~g}$ of plastic and $0.5 \mathrm{~g}$ of catalyst were loaded in the reactor vessel. The catalyst was dried previously in oven at $130{ }^{\circ} \mathrm{C}$ for $30 \mathrm{~min}$ to remove the moisture contents. Initial $\mathrm{H}_{2}$ pressure of 20 bar was then given to the reactor. The temperature of the reactor was allowed to increase till it reached the reaction temperature. The temperature was raised at the rate of $4.6^{\circ} \mathrm{C} / \mathrm{min}$. Residence time of $60 \mathrm{~min}$ was given at

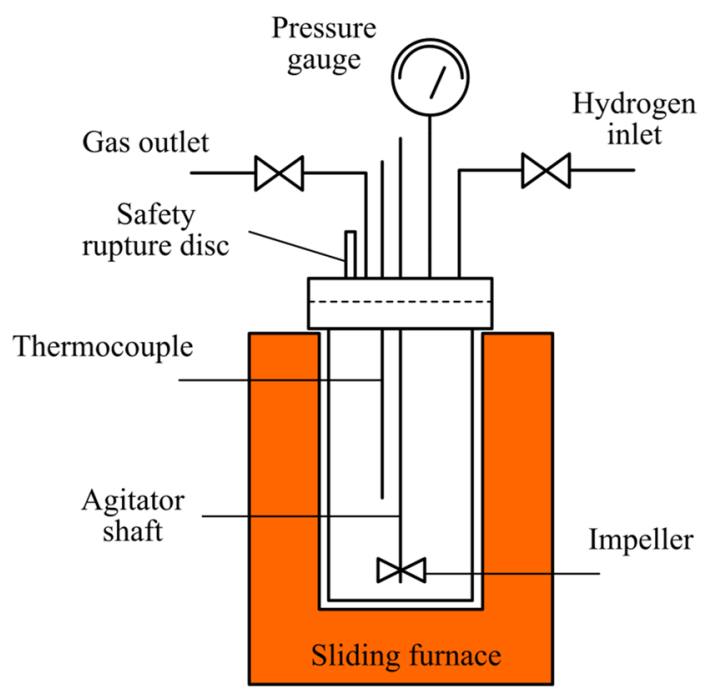

Fig. 1 Experimental setup the reaction temperature. The reactor was then allowed to cool down to the room temperature. The gas release valve was crack-opened to collect the gaseous products. The reactor vessel was then removed and the liquid and solid products were collected. The products were mixed with $n$-heptane ( $\geq 99.0 \%$ purity, Sigma-Aldrich) and the yield of the $n$-heptane solubles was regarded as the oil yield. The $n$-heptane insolubles were then solubilized with tetrahydrofuran ( $\geq 99.0 \%$ purity, Sigma-Aldrich). The sum of the yields of the THF solubles and the $n$-heptane solubles was collectively called as liquid yield. The THF insoluble fraction which might consist of spent catalyst, coke, and unconverted plastic, if any, was dried in an oven and weighed. The conversion for the hydrocracking reaction was defined on the basis of this remaining solid. The yield of the gaseous product was obtained by weighing the reactor at the start (before pressurizing the reactor with hydrogen) and at the end of an experiment (after removing the gases). The term yield was defined as weight of a quantity to the $100 \mathrm{~g}$ of plastic feed fed to the reactor at the start of the experiment. The recovery was calculated as 100 minus the sum of the gas, liquid, and solid yields.

The oil fraction ( $n$-heptane solubles) was additionally analyzed using GC-FID (Shimadzu GC-2014) equipped with $30 \mathrm{~m}$ long and $0.25 \mathrm{~mm}$ inner diameter capillary column (Agilent DB-1MS). This was done to observe the yields of C5-C12 (gasoline), C13-C18 (diesel), and C19+ fractions.

Hydrocracking reactions with model plastic mixture were carried out at three temperatures, namely, $360{ }^{\circ} \mathrm{C}, 375^{\circ} \mathrm{C}$, and $400{ }^{\circ} \mathrm{C}$. The reactions with HDPE (as it is more difficult to degrade compared to LDPE, PP, and PS) and actual waste plastic mixture and the reactions for testing the stability of the catalysts were performed at $400{ }^{\circ} \mathrm{C}$. Actual waste HDPE was washed, cleaned, and dried shampoo bottles, LDPE was unused plastic bags used for the purpose of shopping, PP was unused food containers, and PS was unused tea cups.

\section{Results and discussion}

\section{Characterization of catalysts}

The SEM micrographs of the catalysts are shown in Fig. 2. The micrograph of the commercial beta zeolite (B300) shows ball-like distinct particles that illustrate the characteristic crystals of zeolite beta $[35,36]$. The BC11.1 catalyst shows only a few discrete particles of zeolite beta along with large rough surface agglomerates of irregular shaped morphologies. These rough large agglomerates represent amorphous mesoporous portion. As this catalyst is prepared by the desilication of zeolite beta with $1.5 \mathrm{M} \mathrm{NaOH}$ solution, it seems that desilication has resulted in the destruction of the parent zeolite beta structure. The micrograph of

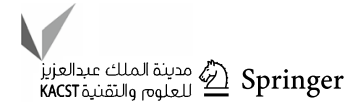


Fig. 2 SEM images of the zeolite beta composite catalysts: a B300, b BC11.1, c BC5.7, d $\mathrm{BC} 0.7$, e BC27, and $\mathbf{f} \mathrm{BC} 48$

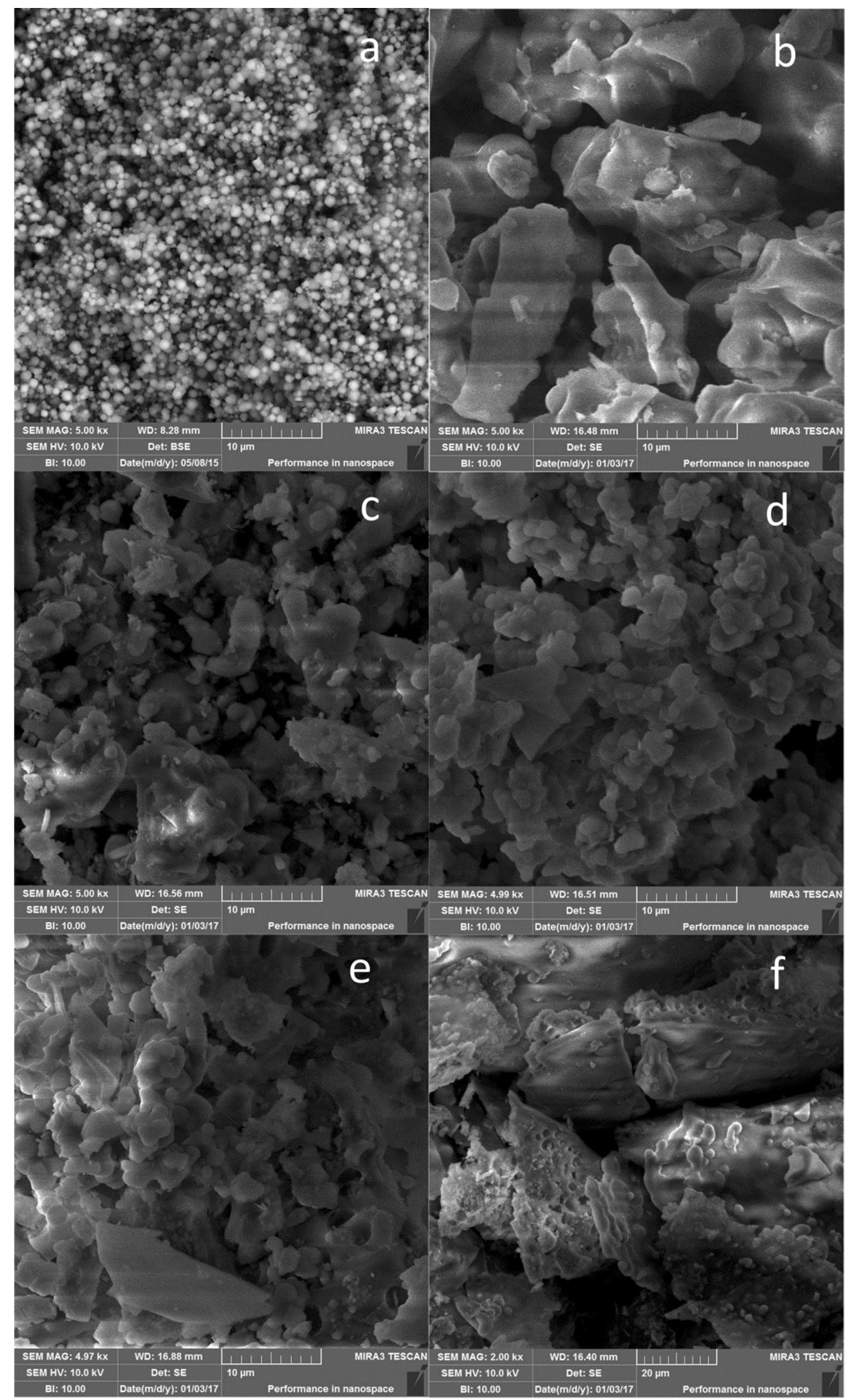

the BC5.7 catalyst displays morphology similar to that of the $\mathrm{BC} 11.1$ catalyst. However, here, compared to BC11.1, more regular shaped zeolite beta particles are present. This can be explained on the basis that lower TEOS/beta ratio was used in the preparation of BC5.7. The morphology of BC0.7 shows higher content of individual crystals of zeolite 
beta. The $\mathrm{BC} 0.7$ catalyst is desilicated with lower molarity of $\mathrm{NaOH}$ solution as compared to $\mathrm{BC} 11.1$. The lower molarity of $\mathrm{NaOH}$ solution resulted in the formation of less distorted structures of zeolite beta. Along with zeolite beta particles, there are irregular shaped aggregates that represent amorphous mesoporous phase. More regular shaped discrete zeolite beta crystals are shown by BC27. As this catalyst was prepared in $0 \mathrm{M} \mathrm{NaOH}$ solution (in the absence of alkali treatment) and there was no desilication, hence no destruction of the zeolite structure is observed. Also, there are some irregularly shaped masses that represent mesoporous content. Compared to BC27, BC48 shows increased amounts of aggregated structures and higher mesoporous silica. Higher hydrothermal treatment time given to BC48 seems to increase the mesoporous portion to a considerable extent.

Figure 3 shows the $\mathrm{N}_{2}$ adsorption-desorption isotherms of the catalysts. The commercial zeolite beta catalyst displays type I isotherm, that is a characteristic isotherm of the microporous zeolitic materials [37]. The isotherms of all the other beta modified catalysts such as BC11.1, BC5.7, $\mathrm{BC} 0.7, \mathrm{BC} 27$, and $\mathrm{BC} 48$ are similar to that of the parent beta catalyst in the region of lower relative pressure. All these catalysts are showing type IV isotherm with characteristic $\mathrm{H} 2$ hysteresis loop [38]. The nature of the isotherms demonstrates the formation of the composite assembly [39] of these catalysts having micropores of zeolite beta present alongside mesoporous silica.

The pore size distribution of the catalysts is depicted in Fig. 4. It is observed that the BC11.1 catalyst is characterized by broad pore size distribution with most of the pore sizes of $3.62 \mathrm{~nm}, 4.15 \mathrm{~nm}$, and $4.75 \mathrm{~nm}$. On the other hand, the BC5.7 and BC0.7 catalysts show bimodal pore size distribution. The former with the lower TEOS/beta ratio has a sharp peak indexed at $3.62 \mathrm{~nm}$ and a small peak at $5.1 \mathrm{~nm}$, whereas

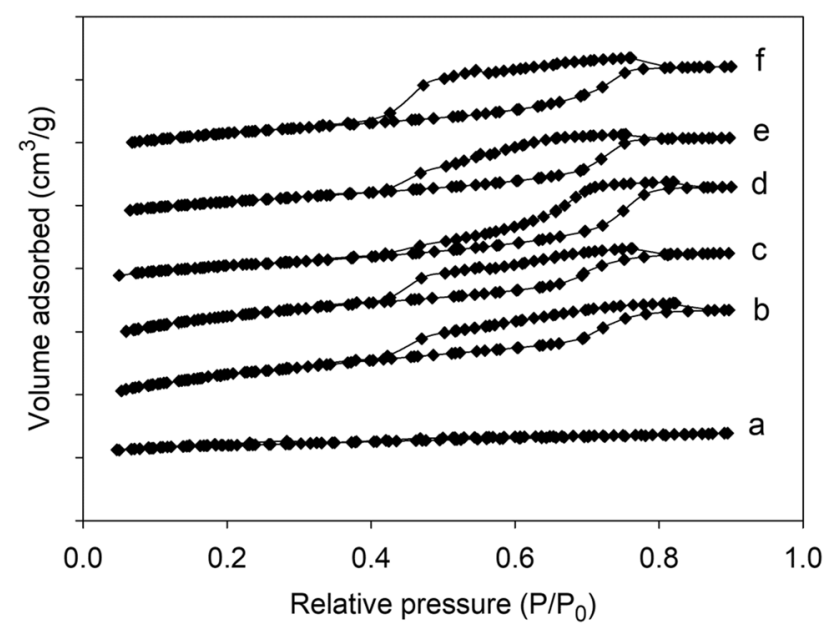

Fig. $3 \mathrm{~N}_{2}$ adsorption-desorption isotherms of the catalysts: a B300, b $\mathrm{BC} 27, \mathbf{c} \mathrm{BC} 48, \mathbf{d} \mathrm{BC} 0.7$, e $\mathrm{BC} 11.1$, and f $\mathrm{BC} 5.7$

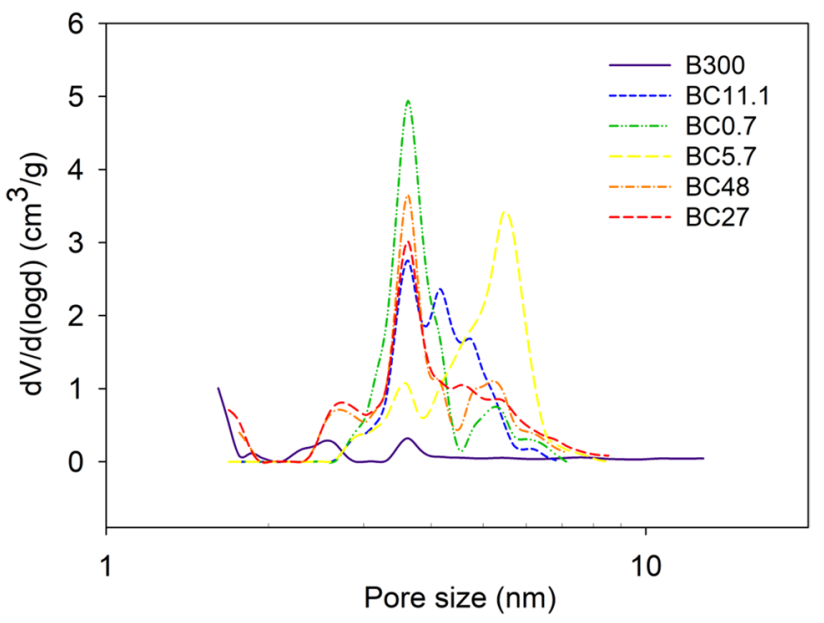

Fig. 4 Pore size distribution of the catalysts

for the latter, most of the pore sizes are of $5.43 \mathrm{~nm}$ with a smaller peak indexed at $3.62 \mathrm{~nm}$. BC27 has the majority of pore sizes of $3.63 \mathrm{~nm}$ and a few of $2.8 \mathrm{~nm}$. With a decrease in molarity of $\mathrm{NaOH}$ solution, there is a trend towards more uniform pore size with bimodal pore size distributions. The catalyst prepared with $0 \mathrm{M} \mathrm{NaOH}$ solution (BC27) has the highest content of micropores along with the mesopores as compared to the other composite catalysts. In the desilicated composite catalysts, however, the parent zeolite beta has also developed some mesopores due to the surface defects created by the extraction of silica from the structure. $\mathrm{BC} 48$ has a narrow pore size distribution with a sharp peak indexed at $3.65 \mathrm{~nm}$ and two smaller peaks at $2.65 \mathrm{~nm}$ and $5.19 \mathrm{~nm}$. The pore size distribution of $\mathrm{BC} 27$ and $\mathrm{BC} 48$ are similar and both the catalysts have nearly the same distribution around $2.65 \mathrm{~nm}$ and $3.65 \mathrm{~nm}$. However, in the case of $\mathrm{BC} 27$, there is an increased amount of micropores, whereas BC48 has a significant quantity of mesopores. It is, therefore, revealed that an increase in hydrothermal treatment time has resulted in a decrease of micropore quantity and an increase in the amount of mesopores with larger pore size.

The structural properties of the catalysts from nitrogen physisorption are shown in Table 1. The highest surface area is found in $\mathrm{BC} 27$ that is followed by BC48. Both of these catalysts are composite catalysts of zeolite beta without any desilication treatment. The surface area of all the desilicated catalysts (BC11.1, BC5.7, and BC0.7) is lower than that of the parent beta catalyst. Among the composite catalysts, the highest micropore volume is given by $\mathrm{BC} 27$ followed by $\mathrm{BC} 48$. All these results strengthen the fact that the structure of zeolite beta in the desilicated composites is distorted, whereas in $\mathrm{BC} 27$ and $\mathrm{BC} 48$, the structure of zeolite beta is intact in the final composite catalyst. Therefore, zeolite beta along with the mesoporous silica have coherently contributed towards the increase in the surface area

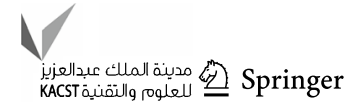


Table 1 Structural properties of the zeolite beta composite catalysts

\begin{tabular}{lcllllllll}
\hline Catalyst & $\begin{array}{l}\text { TEOS/B300 } \\
(\mathrm{wt} / \mathrm{wt})\end{array}$ & $t_{\mathrm{h}}(\mathrm{h})$ & $\begin{array}{l}\mathrm{NaOH} \\
\text { molarity } \\
(\mathrm{M})\end{array}$ & $S_{\mathrm{g}}\left(\mathrm{m}^{2} / \mathrm{g}\right)$ & $S_{\mathrm{mi}}\left(\mathrm{m}^{2} / \mathrm{g}\right)$ & $\mathrm{BJH} S_{\mathrm{g}}\left(\mathrm{m}^{2} / \mathrm{g}\right)$ & $v_{\mathrm{mp}}\left(\mathrm{cm}^{3} / \mathrm{g}\right)$ & $\mathrm{BJH} v_{\mathrm{p}}\left(\mathrm{cm}^{3} / \mathrm{g}\right)$ & $\mathrm{BJH} d_{\mathrm{p}}(\mathrm{nm})$ \\
\hline B300 & - & - & - & 581.9 & 465.4 & 43.44 & 0.210 & 0.0465 & 3.23 \\
BC11.1 & 11.1 & 27 & 1.5 & 408.40 & 43.01 & 165.4 & 0.0105 & 0.1999 & 6.49 \\
BC5.7 & 5.7 & 27 & 1.5 & 475.5 & 51.79 & 192.2 & 0.01104 & 0.2389 & 6.50 \\
BC0.7 & 11.1 & 27 & 0.7 & 399.1 & 11.35 & 185.5 & 0.00453 & 0.222 & 6.50 \\
BC27 & 11.1 & 27 & 0 & 775.4 & 309.1 & 180.7 & 0.123 & 0.207 & 6.40 \\
BC48 & 11.1 & 48 & 0 & 719.2 & 229.1 & 198.1 & 0.0856 & 0.249 & 6.48 \\
\hline
\end{tabular}

$t_{h}$ is hydrothermal treatment time, $S_{g}$ is surface area using BET method, $S_{m i}$ is micropore area obtained by t-plot, $B J H S_{g}$ is BJH adsorption cumulative surface area of the pore between $17 \AA$ and $3000 \AA$ width, $v_{m p}$ is micropore volume obtained by t-plot, $B J H v_{p}$ is BJH adsorption cumulative volume of the pore between $17 \AA$ and $3000 \AA$ width, and $B J H d_{p}$ is BJH adsorption average pore diameter

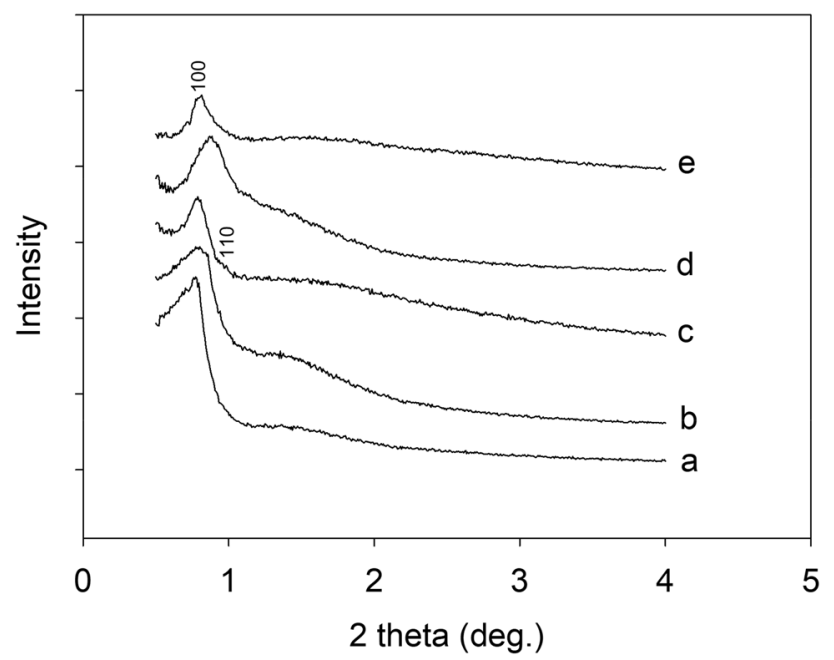

Fig. 5 Small-angle XRD patterns of the catalysts: a BC11.1, b BC5.7, c BC48, d BC0.7, and e BC27

of these catalysts. The highest $\mathrm{BJH}$ pore volume is found in BC48. This catalyst has found to contain the highest mesoporous content confirmed also by the other characterization techniques.

Figure 5 shows the small-angle X-ray analysis of the catalysts. All the composite catalysts exhibit a well-resolved peak at $2 \theta$ value of around 0.78 ( 0.88 in the case of $\mathrm{BC} 0.7)$ that corresponds to (100) reflection. A tiny peak is present in nearly all the catalysts at $2 \theta$ value of around 0.98 (relatively strong in BC27 and BC48 and weak in the other catalysts) that correspond to (110) reflection [40]. All the catalysts possess many small peaks at $2 \theta$ value of 1.10-2.90 which are not well resolved and difficult to differentiate. The results indicate the presence of mesostructure with low order [41, 42] that might be attributed to higher $\mathrm{pH}$ of the hydrogel mixture before the hydrothermal treatment in the synthesis step. The $\mathrm{pH}$ of the mixture was maintained to a value of 4 before the hydrothermal treatment to prevent the chances

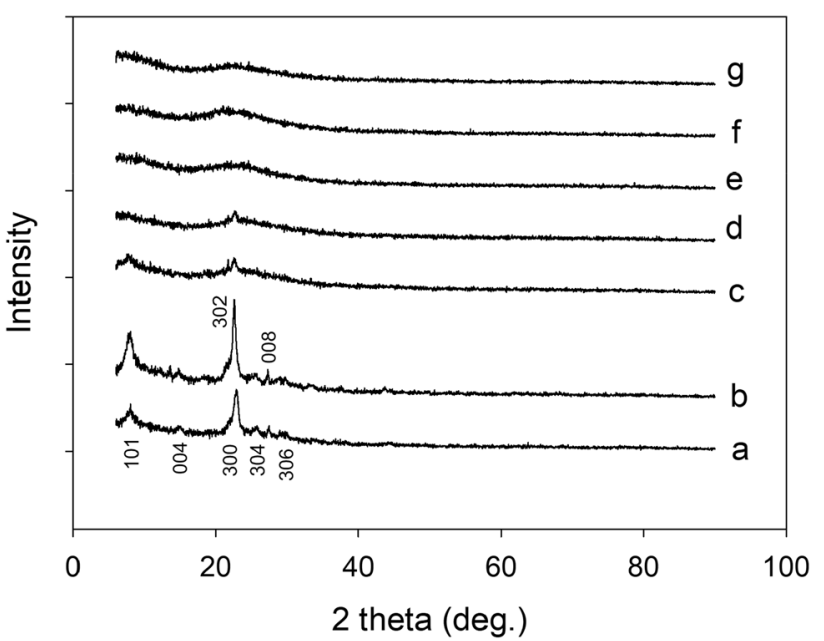

Fig. 6 Wide-angle XRD patterns of the catalysts: a B300, b BC27, c BC48, d BC5.7, e BC11.1, and f BC0.7

of aluminum leaching. Low-order structure could also be resulted from the co-existence of cubic and hexagonal mesostructures in the catalysts.

The wide-angle X-ray diffractogram of the commercial zeolite beta shown in Fig. 6 presents well-resolved peaks that are characteristic features of a highly crystalline zeolite beta. The diffractograms of the composite catalysts with desilication treatment (BC11.1, BC5.7, and BC0.7) indicate the destruction of highly crystalline structure of the zeolite beta in these composites. As a result, these catalysts are showing the diffraction pattern similar to that of an amorphous catalyst. In other words, the zeolite beta structure is appeared to collapse significantly by the desilication and the resulting diffraction patterns of these catalysts are contributed by the mesoporous silica content. The decrease in the crystallinity is also observed in the catalysts prepared without desilication due to the introduction of mesoporosity and not due to the damage to the crystal structure of the catalysts by desilication. Among all the composite catalysts, 
$\mathrm{BC} 27$ is found to be the most crystalline catalyst. Increasing time of hydrothermal treatment results in the degradation of the crystalline structure of $\mathrm{BC} 48$ compared to $\mathrm{BC} 27$ indicating the presence of better mesostructure in $\mathrm{BC} 48$. This fact is also confirmed by the results obtained with SEM and nitrogen physisorption.

Figure 7 shows the Py-FTIR spectra of the catalysts. All the catalysts except $\mathrm{BC} 0.7$ show an intensified band at $1628 \mathrm{~cm}^{-1}$ that corresponds to pyridine association with strong Lewis acid sites [43, 44]. BC11.1, BC48, and BC27 exhibit less intensified bands at $1545 \mathrm{~cm}^{-1}$ and $1485 \mathrm{~cm}^{-1}$ that indicate the presence of Brønsted acid sites [43] and Lewis + Brønsted acid sites, respectively $[40,45]$. The $\mathrm{B} 300$ and BC0.7 catalysts have a band at about $1540 \mathrm{~cm}^{-1}$ assigned to Brønsted acid sites [43]. BC0.7 is found to contain the lowest amount of acid sites. Out of all the catalysts, mesoporous composites $\mathrm{BC} 48$ and $\mathrm{BC} 27$ have shown to have the highest amount of acid sites more than B300.

The FTIR spectra of the catalysts representing the atomic level connections of the chemical bonds in the catalysts are shown in Fig. 8. A transmission band at $557 \mathrm{~cm}^{-1}$ exists in $\mathrm{B} 300, \mathrm{BC} 48$, and $\mathrm{BC} 27$ that corresponds to the vibrational mode of a typical zeolite beta structure having 5 or 6 membered rings of T-O-T in zeolites [36]. This band is almost absent in the other catalysts resulted from the

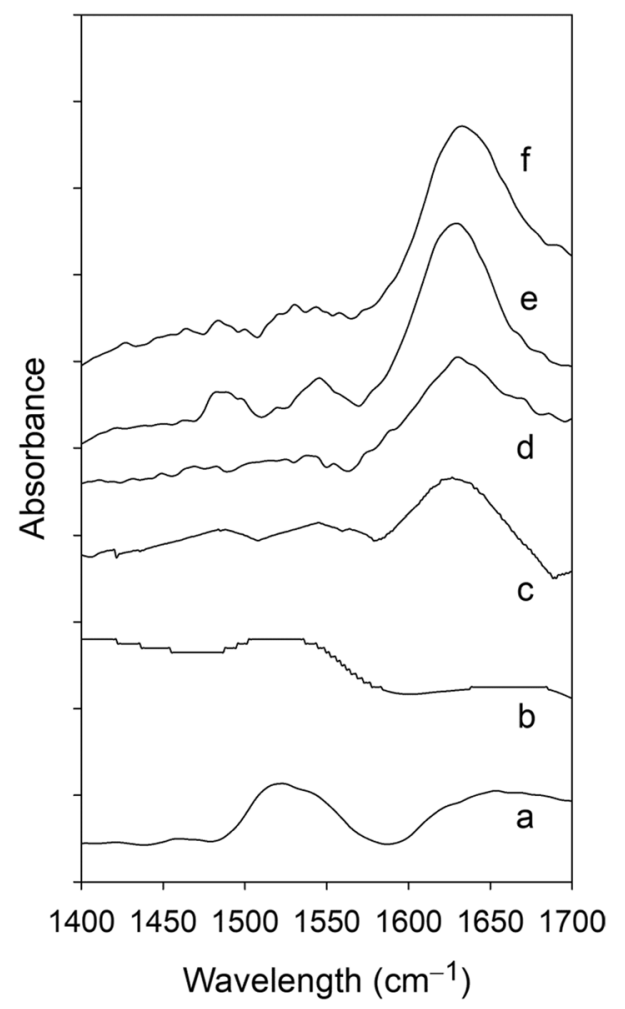

Fig. 7 FTIR spectra of the pyridine adsorbed catalysts: a B300, b $\mathrm{BC} 0.7, \mathbf{c} \mathrm{BC} 27, \mathbf{d} \mathrm{BC} 5.7, \mathbf{e} \mathrm{BC} 11.1$, and $\mathbf{f} \mathrm{BC} 48$

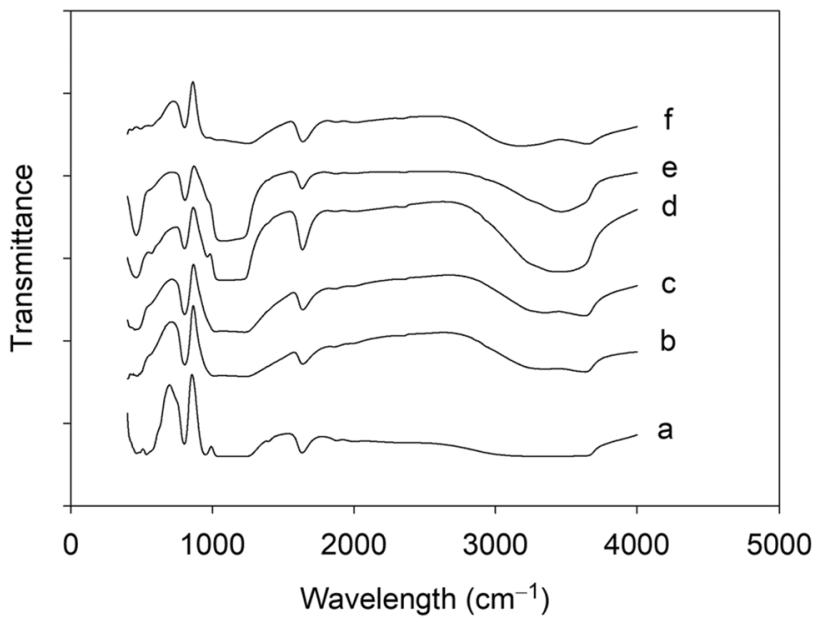

Fig. 8 FTIR spectra of the catalysts: a B300, b BC11.1, c BC5.7, d $\mathrm{BC} 48$, e BC0.7, and f $\mathrm{BC} 27$

desilication by $\mathrm{NaOH}$ solution suggesting damage to the zeolite beta crystalline structure to some extent. All the catalysts exhibit the transmission bands at $464 \mathrm{~cm}^{-1}$ and $1045 \mathrm{~cm}^{-1}$ that are attributed to T-O bond stretching vibration and bending vibration, respectively [45]. Another significant band is observed in all the catalysts at $800 \mathrm{~cm}^{-1}$ that corresponds to T-O-T bond symmetric stretching [46]. The band at $950 \mathrm{~cm}^{-1}$ is assigned to the stretching vibration of $\mathrm{Si}-\mathrm{OH}[47,48]$. There is a broad peak in each catalyst from $1034-1250 \mathrm{~cm}^{-1}$ that is assigned to the asymmetric stretching of $\mathrm{Si}-\mathrm{O}-\mathrm{Si}$ bond [20]. Furthermore, each catalyst exhibits a broad band at $3677 \mathrm{~cm}^{-1}$ which is attributed to the bond vibration of the terminal silanol group [40]. Another important band is also observed at $1663 \mathrm{~cm}^{-1}$ which indicates $-\mathrm{OH}$ bond flexural vibration [46].

\section{Catalytic hydrocracking performance of the catalysts}

The results of the hydrocracking experiments with model plastic mixture, actual waste plastic mixture, and HDPE are discussed in the following sections. On average greater than $95 \%$ (by weight), recovery was obtained. All the results of experimentation are tabulated in Table S1.

\section{Reactions with model plastic mixture}

Figure 9 shows the results of experimentation with model plastic mixture at three different temperatures $\left(360{ }^{\circ} \mathrm{C}\right.$, $375^{\circ} \mathrm{C}$, and $400{ }^{\circ} \mathrm{C}$ ). It is observed that at the reaction temperature of $360{ }^{\circ} \mathrm{C}$, the lowest reaction temperature, $\mathrm{BC} 48$ delivered the highest conversion with the highest liquid and oil yields, whereas BC27 closely followed it. Both BC27 and BC48 exhibited much better activity and selectivity towards

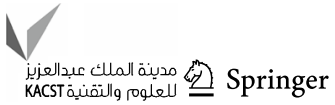



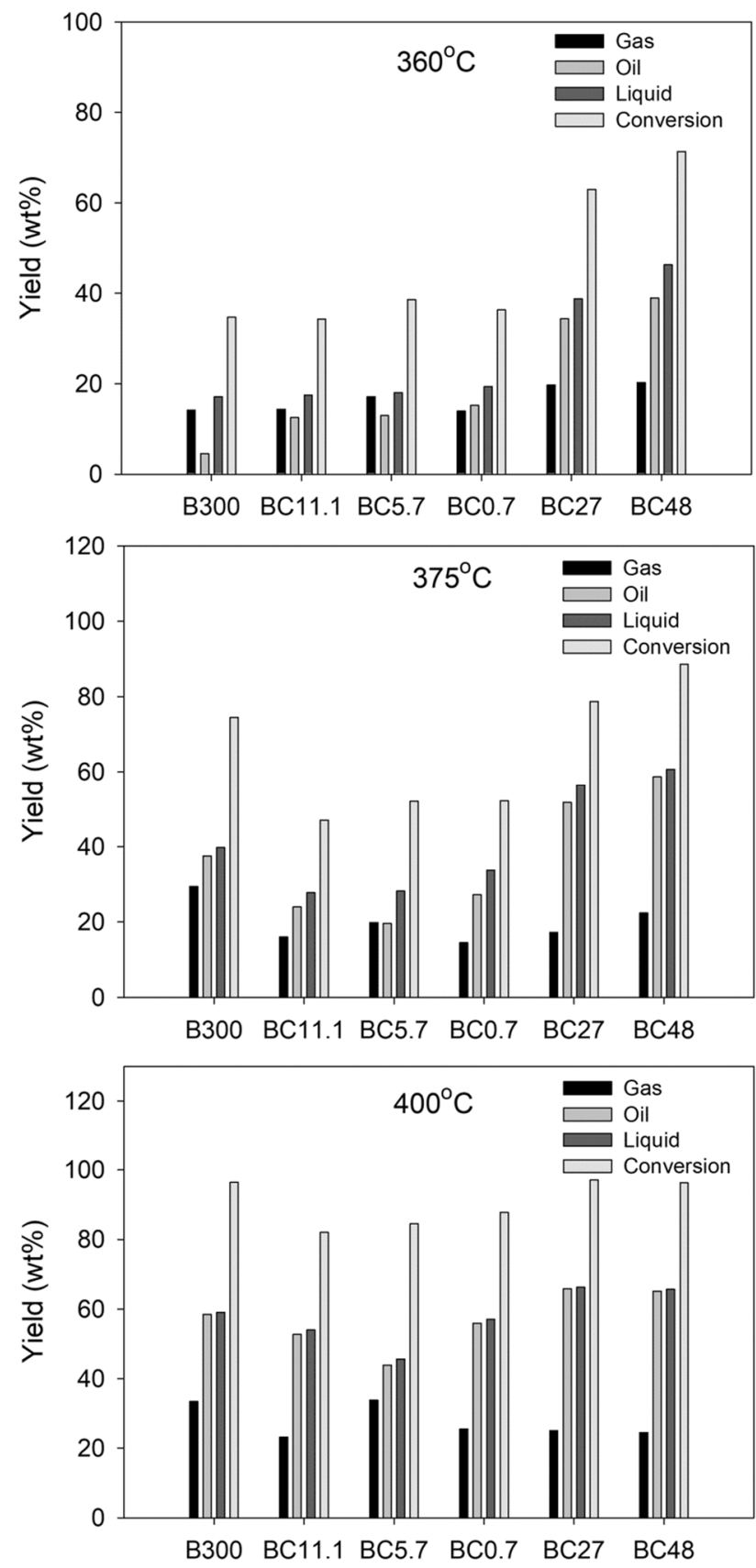

Fig. 9 Results of the catalytic hydroconversion reactions of model plastic mixture over different catalysts. $500 \mathrm{ml}$ autoclave reactor, 20 bar initial cold hydrogen pressure, 60 min residence time, and 20:1 feed-to-catalyst ratio (by weight)

the liquids in comparison to all the other catalysts employed in the study. Clearly, the commercial zeolite beta (B300), due to its microporous nature, has shown greatly reduced activity and selectivity towards the liquid. The two micromesoporous composite catalysts, $\mathrm{BC} 27$ and $\mathrm{BC} 48$, were synthesized without desilication of the parent zeolite. Alkali treatment perhaps damaged the crystal structure and aided in the loss of the activity, whereas no-desilication maintained the microporous crystallinity of the composite catalysts and resulted in improved performance of the catalysts. Moreover, increase in the hydrothermal treatment time resulted in higher mesoporous area of $\mathrm{BC} 48$ than that of $\mathrm{BC} 27$. The increased mesoporous area facilitated the improved diffusion of the initially cracked higher molecular weight polymeric fragments and the cracked liquid products through the pores of the catalysts. An enhanced activity and desired selectivity of $\mathrm{BC} 48$ catalyst over $\mathrm{BC} 27$ catalyst was, therefore, possible. Additionally, as observed in Table 1, both BC27 and BC48 have the highest surface area, in fact, much larger than the surface area of all the other catalysts. Also, they have appreciable surface due to both the micropores and the mesopores compared to rest of the catalysts where only one of the areas has significant value. As an example, for $\mathrm{BC} 27$, the total surface area is $775.4 \mathrm{~m}^{2} / \mathrm{g}$ and microporous and mesoporous surfaces are $309.1 \mathrm{~m}^{2} / \mathrm{g}$ and $180.7 \mathrm{~m}^{2} / \mathrm{g}$, respectively. On the other hand, for B 300 , the total surface area is $508.1 \mathrm{~m}^{2} / \mathrm{g}$, while the micro and meso surface areas are $465.4 \mathrm{~m}^{2} / \mathrm{g}$ and $43.44 \mathrm{~m}^{2} / \mathrm{g}$, respectively. For BC5.7 having $475.5 \mathrm{~m}^{2} / \mathrm{g}$ total surface area, micropore area is $51.79 \mathrm{~m}^{2} / \mathrm{g}$ and mesopore area is $192.2 \mathrm{~m}^{2} / \mathrm{g}$. The presence and perhaps better distribution of both the micropores and mesopores seem the reason for the increased activity of the $\mathrm{BC} 27$ and $\mathrm{BC} 48$ catalysts.

At $375^{\circ} \mathrm{C}$, again the same two catalysts $\mathrm{BC} 27$ and $\mathrm{BC} 48$ showed the increased conversion and liquid yield. However, at this temperature the parent B300 catalyst also showed improved performance, though, the catalyst produced the highest gas yield. High gas yields with B300 might be explained by its dominant microporous character. The desilicated catalysts still showed unsatisfactory performance. As mentioned before, this last result might be attributed to the structural damage to the parent zeolite in the desilicated catalysts which is also evident from the characterization of the alkali-treated catalysts. The structural damage to the parent zeolite may suggest that the performance of the desilicated catalysts corresponds only to the mesoporous content of these catalysts.

At the reaction temperature of $400{ }^{\circ} \mathrm{C}$, the parent zeolite beta (B300), BC27, and BC48 have shown similar activities. However, $\mathrm{BC} 27$ and $\mathrm{BC} 48$ catalysts produced the highest amount of liquids whereas B300 provided higher gas yields. Moreover, the desilicated catalysts maintained their poor performance with respect to both the activity and the liquid selectivity.

The results of gas chromatography of the oil fractions obtained at three reaction temperatures are shown in Fig. 10. It is found that at each temperature, the B300 catalyst showed increased selectivity for the gasoline product. It may correspond to the micropores present in B300 that allowed low molecular weight molecules of gasoline range to leave in the gas phase relatively easily. The $\mathrm{BC} 27$ and $\mathrm{BC} 48$ catalysts also produced increased gasoline content. Gasoline fraction 

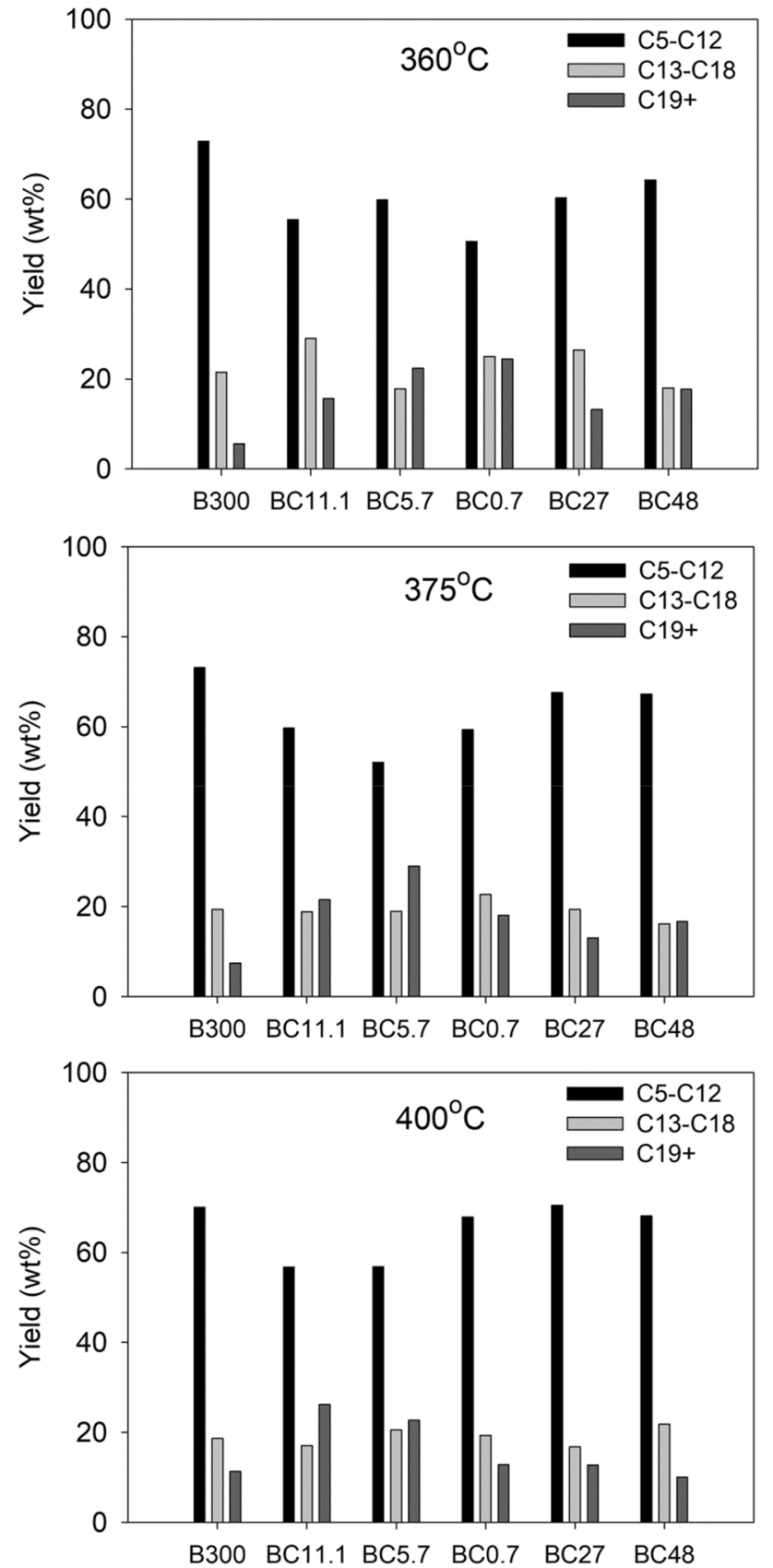

Fig. 10 Results of GC analysis of the $n$-heptane soluble liquids obtained by the catalytic hydroconversion of model plastic mixture over different catalysts. $500 \mathrm{ml}$ autoclave reactor, 20 bar initial cold hydrogen pressure, 60 min residence time, and 20:1 feed-to-catalyst ratio (by weight)

of these two catalysts is close to that obtained with B300, at the higher reaction temperatures of $375^{\circ} \mathrm{C}$ and $400{ }^{\circ} \mathrm{C}$. With increase in reaction temperature, the light diesel component over BC27 and the heavy diesel component over BC48 were converted into gasoline. Increase in reaction temperature might have resulted in the breakdown of heavy molecular chains of light and heavy diesel components. Generally, all

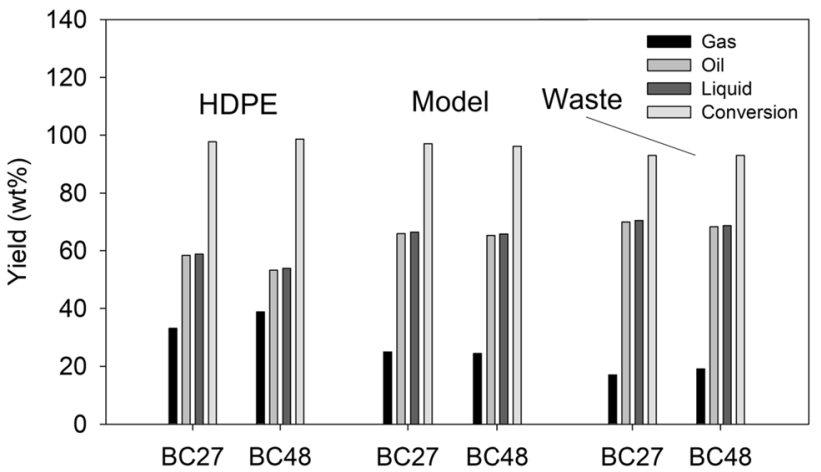

Fig. 11 Results of the catalytic hydroconversion reactions of indicated plastic materials over BC27 and BC48 catalysts. $500 \mathrm{ml}$ autoclave reactor, 20 bar initial cold hydrogen pressure, 60 min residence time, and 20:1 feed-to-catalyst ratio (by weight)

the desilicated catalysts produced much lower gasoline fraction but greater diesel fractions than that of B300, BC27, and $\mathrm{BC} 48$.

\section{Reactions with actual waste plastic mixture}

Both $\mathrm{BC} 48$ and $\mathrm{BC} 27$ catalysts were found the most active and selective catalysts in the hydrocracking experiments with model plastic mixture. These two catalysts were, therefore, further exploited to study their cracking performance with actual waste plastic mixture. The experiments were carried out under the reaction conditions of $400{ }^{\circ} \mathrm{C}, 20 \mathrm{bar}$ initial cold $\mathrm{H}_{2}$ pressure, 60 min reaction time, and 20:1 (by weight) feed-to-catalyst ratio.

The results of experimentation with waste plastic mixture and their comparison with model plastic mixture (and HDPE) are shown in Fig. 11. It is found that both BC27 and $\mathrm{BC} 48$ provided nearly the same conversion. However, BC27 showed a slightly improved performance with respect to liquid and gas yields. It is observed that the conversion of BC27 and BC48 was only slightly decreased when waste plastic mixture was employed compared to when experiments were conducted with HDPE or model plastic mixture. However, a slight improvement in the liquid yield with corresponding decreased amounts of gases is observed with actual waste plastic mixture. These results show that the two catalysts are appropriate in handling the waste plastic material. The performance of the catalysts may also be dedicated to the presence of hydrogen which, in the presence of a catalyst, can carry out hydrotreating of the impurities [17] that may hinder the performance of the catalysts.

The gas chromatography results (Fig. 12) show that gasoline yield is somewhat decreased with waste plastic mixture in comparison to model plastic mixture. Comparing $\mathrm{BC} 27$ and $\mathrm{BC} 48, \mathrm{BC} 27$ has shown better gasoline and diesel yields with the actual waste plastic mixture. Higher gasoline content of

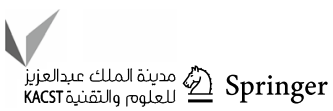




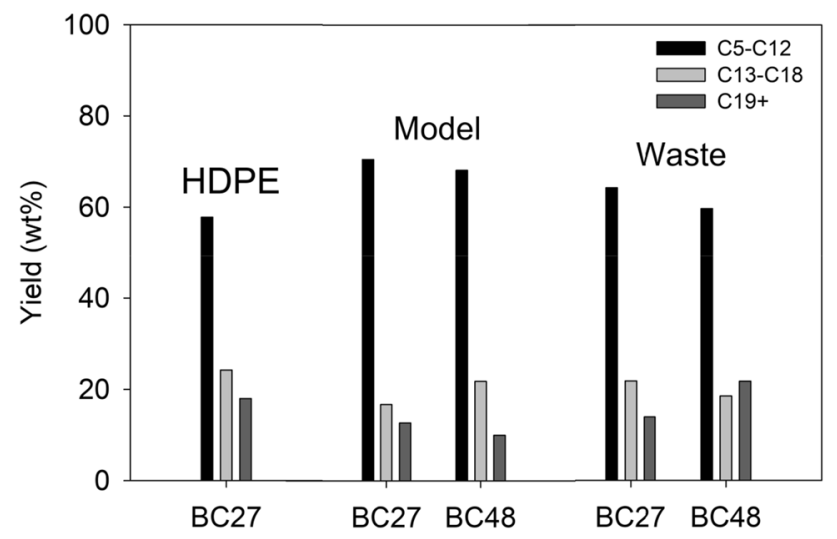

Fig. 12 Results of GC analysis of the $n$-heptane soluble liquids obtained by the catalytic hydroconversion of indicated plastic materials over BC27 and BC48. $500 \mathrm{ml}$ autoclave reactor, 20 bar initial cold hydrogen pressure, 60 min residence time, and 20:1 feed-to-catalyst ratio (by weight)

$64.3 \mathrm{wt} \%$ is produced by $\mathrm{BC} 27$, while $\mathrm{BC} 28$ yields $59.7 \mathrm{wt} \%$ gasoline.

\section{Hydrocracking reactions with HDPE}

Hydrocracking reactions with HDPE over BC27 and BC48 under reaction conditions of $400{ }^{\circ} \mathrm{C}, 20$ bar cold $\mathrm{H}_{2}$ pressure, 60 min reaction time, and 20:1 (by weight) feed-to-catalyst ratio are shown in Fig. 11. The results revealed that both catalysts again yielded nearly similar conversion of about $100 \%$ and again BC27 showed slightly improved performance with regard to gas and liquid yields. The higher liquid yield of $58.8 \mathrm{wt} \%$ and the lowest gas yield of $33.2 \%$ were produced by the $\mathrm{BC} 27$ catalyst. It is found that both catalysts for the reactions of HDPE yielded nearly the same conversion, but lower amount of liquid yield, and significantly higher gas yield compared to their corresponding reactions with model plastic mixture. This is reasonable and can be explained on the basis that the model plastic mixture contains significant amounts of PS, PP, and LDPE which are expected to produce higher liquid products [5]. Moreover, the interaction among the various plastics can result in the formation of higher liquid content obtained by the hydrocracking of model plastic mixture [49].

The GC analysis of $n$-heptane solubles for BC27 shows that the amount of gasoline obtained with HDPE is reduced to $57.8 \%$ in comparison to $70.53 \%$ with model plastic mixture, correspondingly higher yields of light diesel and heavy diesel are obtained with HDPE.

\section{Stability study of the catalysts with and without regenerating the catalysts}

Hydrocracking reactions with coked (dried spent) catalysts The stability of the catalysts was analyzed using the

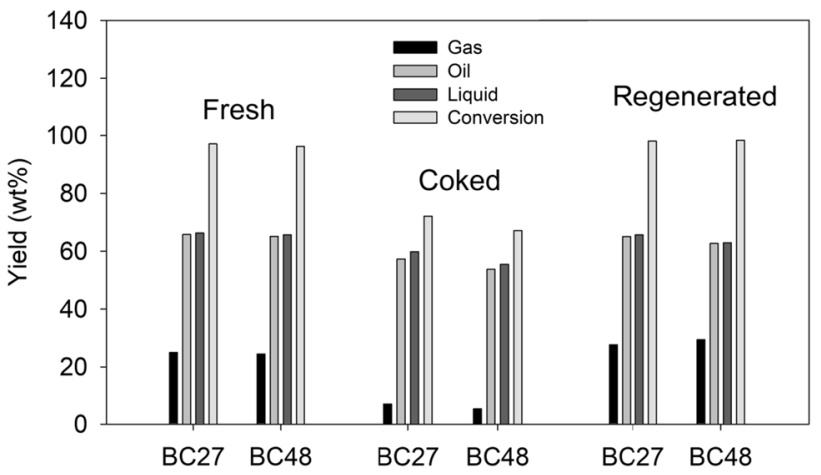

Fig. 13 Results of the stability test of $\mathrm{BC} 27$ and $\mathrm{BC} 48$ catalysts for the catalytic hydroconversion reaction of model plastic mixture. $500 \mathrm{ml}$ autoclave reactor, 20 bar initial cold hydrogen pressure, 60 min residence time, and 20:1 feed-to-catalyst ratio (by weight)

spent (coked) catalysts for the hydrocracking reactions with model plastic mixture. The spent catalyst was obtained from an earlier experiment with model plastic mixture using $500 \mathrm{ml}$ autoclave, $60 \mathrm{~min}$ of residence time, $400{ }^{\circ} \mathrm{C}$ of reaction temperature, and 20 bar initial cold hydrogen pressure. The spent catalyst was subjected to drying in an oven for 30 min at $120^{\circ} \mathrm{C}$. The dried spent catalyst was mixed with the fresh catalyst in $1: 1$ ratio by weight to compensate the loss of the used catalyst and to maintain the same feed-tocatalyst ratio. The spent catalyst was then employed for the cracking reaction with model plastic mixture under the same reaction conditions as discussed above for the case of an earlier reaction. The results obtained are shown in Fig. 13.

It is found that $\mathrm{BC} 27$ and $\mathrm{BC} 48$ produced significantly lower conversions in the stability runs as compared to their reactions over the fresh catalysts. Also, the liquid yield and the gas yield obtained over both the coked catalysts is lower to that obtained with the fresh catalyst. Among the two catalysts, $\mathrm{BC} 27$ produced higher conversion, $72.2 \mathrm{wt} \%$, and higher liquid yield, 59.9wt\% suggesting $\mathrm{BC} 48$ was more prone to coking. A catalyst with higher mesoporosity (BC48) allows the greater production of heavier compounds thus might result in increased coke formation.

The gas chromatography analysis of $n$-heptane soluble liquids from the stability reactions is displayed in Fig. 14. When compared to the reactions over fresh catalysts, it is found that the spent catalysts are less selective towards gasoline than their corresponding fresh catalysts. Comparing the $\mathrm{BC} 27$ and $\mathrm{BC} 48$ catalysts, it is observed that $\mathrm{BC} 27$ produced higher gasoline content of $41.6 \%$ than that of $\mathrm{BC} 48$, which is more selective towards heavy diesel.

Hydrocracking reactions with regenerated (calcined spent) catalysts The stability of the catalysts was further analyzed using regenerated catalysts with model plastic mixture. The spent catalysts were calcined in air to remove the carbo- 


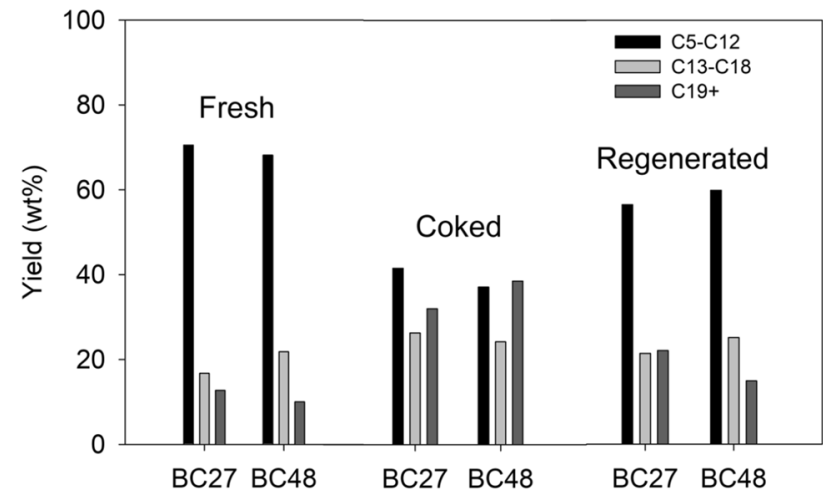

Fig. 14 Results of GC analysis of the $n$-heptane soluble liquids obtained during the stability test of $\mathrm{BC} 27$ and $\mathrm{BC} 48$ catalysts for the catalytic hydroconversion reaction of model plastic mixture. $500 \mathrm{ml}$ autoclave reactor, 20 bar initial cold hydrogen pressure, 60 min residence time, and 20:1 feed-to-catalyst ratio (by weight)

naceous deposits from their surface. Each of the calcined spent catalysts was mixed with equal amount by weight of the corresponding fresh catalyst and the experiments were performed under the same reaction conditions as discussed above. The results of the hydrocracking reactions over the regenerated catalysts are shown in Fig. 13. Generally, both the catalysts yielded comparable conversion and the product yields to that of the fresh catalysts. The regenerated BC48 catalyst produced relatively higher gas yield and lower liquid yield than its corresponding fresh catalyst. The reason might be assigned to the increase in active sites of the catalysts due to calcination that decomposed the coke deposited on the active sites. Also, some sintering of the particles might occur reducing the average pore size of the catalysts thereby generating increased amounts of gases with reduced quantities of liquids.

The gas chromatography of the $n$-heptane solubles revealed that the regenerated catalysts yielded rather decreased amount of gasoline compared to the fresh catalysts. However, they provided significantly improved amount of gasoline compared to the coked catalysts. Coked catalysts provided significantly increased amount of heavier liquids.

\section{Conclusion}

The results of the catalyst characterization confirmed the formation of micro-mesoporous composite materials. The catalysts (BC11.1, BC5.7, and $\mathrm{BC} 0.7)$ prepared by the desilication of the parent zeolite beta performed poorly in the hydrocracking reactions. On the other hand, the catalysts (BC48 and BC27) prepared without alkali pretreatment resulted in significantly greater liquid yields, lower gas yields, and higher plastic conversions. For the two catalysts, the GC analyses of the $n$-heptane solubles also showed the enhanced selectivity towards gasoline. Comparing $\mathrm{BC} 48$ and $\mathrm{BC} 27$, it is observed that overall $\mathrm{BC} 48$ performed better than $\mathrm{BC} 27$ as it produced more liquid yield and higher conversion, especially at reduced temperatures. GC analysis of $n$-heptane soluble also showed increased selectivity of BC48 over BC27 towards gasoline. The appropriate distribution of micropores and mesopores in the former might be the reason behind its better action.

Additional experiments with actual waste plastic mixture showed the comparable performance of these catalysts with the model plastic mixture. With high-density polyethylene, however, lower liquid yields and higher gas yields were obtained. When tested for the stability of the catalysts, coked catalysts yielded far less conversion and were selective in producing heavier liquid fractions, whereas regenerated (by calcination in air) catalysts showed comparable results to the fresh catalysts apart from giving somewhat reduced amount of gasoline.

Acknowledgements The authors acknowledge Higher Education Commission of Pakistan for funding the work under the Project No. 20-2308/NRPU/R\&D/HEC/12470. Also, the authors acknowledge Dr. Muhammad Faisal Irfan for providing commercial zeolite beta catalyst.

Open Access This article is licensed under a Creative Commons Attribution 4.0 International License, which permits use, sharing, adaptation, distribution and reproduction in any medium or format, as long as you give appropriate credit to the original author(s) and the source, provide a link to the Creative Commons licence, and indicate if changes were made. The images or other third party material in this article are included in the article's Creative Commons licence, unless indicated otherwise in a credit line to the material. If material is not included in the article's Creative Commons licence and your intended use is not permitted by statutory regulation or exceeds the permitted use, you will need to obtain permission directly from the copyright holder. To view a copy of this licence, visit http://creativecommons.org/licenses/by/4.0/.

\section{References}

1. Brems, A., Baeyens, J., Dewil, R.: Recycling and recovery of postconsumer plastic solid waste in a European context. Therm. Sci. 16, 669-675 (2012)

2. Sarker, M., Rashid, M.M., Molla, M.: Waste plastic conversion into chemical product like naphtha. J. Fundam. Renew. Energ. Appl. 1, 1-6 (2011)

3. Arandes, J.M., Abajo, I., Lopez-Valerio, D., Fernandez, I., Azkoiti, M.J., Olazar, M., Bilbao, J.: Transformation of several plastic wastes into fuels by catalytic cracking. Ind. Eng. Chem. Res. 36, 4523-4529 (1997)

4. Pinto, F., Costa, P., Gulyurtlu, I., Cabrita, I.: Pyrolysis of plastic wastes: effect of plastic waste composition on product yield. J. Anal. Appl. Pyrolysis 5, 39-45 (1999)

5. Munir, D., Irfan, M.F., Usman, M.R.: Hydrocracking of virgin and waste plastics: a detailed review. Renew. Sust. Energy Rev. 90, 490-515 (2018)

6. Zmierczak, W., Xiao, X., Shabtai, J.: Depolymerization-liquefaction of plastics and rubbers. 2. Polystyrenes and styrene-butadiene copolymers. Fuel. Process. Technol. 49, 31-38 (1996)

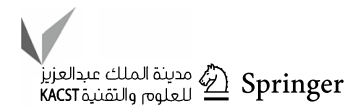


7. Serrano, D.P., Aguado, J., Escola, J.M., Rodríguez, J.M., Morselli, L., Orsi, R.: Thermal and catalytic cracking of a LDPEEVA copolymer mixture. J. Anal. Appl. Pyrolysis 68-69, 481-494 (2003)

8. Miskolczi, N., Bartha, L., Deák, G., Jóver, B.: Thermal degradation of municipal plastic waste for production of fuel-like hydrocarbons. Polym. Degrad. Stab. 86, 357-366 (2004)

9. Aguado, J., Serrano, D.P., San Miguel, G., Escola, J.M., Rodríguez, J.M.: Catalytic activity of zeolitic and mesostructured catalysts in the cracking of pure and waste polyolefins. J. Anal. Appl. Pyrolysis 78, 153-161 (2007)

10. Hesse, N.D., White, R.L.: Polyethylene catalytic hydrocracking by PtHZSM-5, PtHY, and PtHMCM-41. J. Appl. Polym. Sci. 92, 1293-1301 (2004)

11. Jan, M.R., Shah, J., Gulab, H.: Catalytic degradation of waste high-density polyethylene into fuel products using $\mathrm{BaCO}_{3}$ as a catalyst. Fuel Process. Technol. 91, 1428-1437 (2010)

12. Toledo, J.M., Aznar, M.P., Sancho, J.A.: Catalytic air gasification of plastic waste (polypropylene) in a fluidized bed, Part II: Effects of some operating variables on the quality of the raw gas produced using olivine as the in-bed material. Ind. Eng. Chem. Res. 50, 1815-1821 (2011)

13. Wang, J.L., Wang, L.L.: Catalytic pyrolysis of municipal plastic waste to fuel with nickel-loaded silica-alumina catalysts. Energy Sources Part A 33, 1940-1948 (2011)

14. Feng, Z., Zhao, J., Rockwell, J., Bailey, D., Huffman, G.: Direct liquefaction of waste plastics and coliquefaction of coal-plastic mixtures. Fuel Process. Technol. 49, 17-30 (1996)

15. Liu, K., Meuzelaar, H.L.: Catalytic reactions in waste plastics, HDPE and coal studied by high-pressure thermogravimetry with on-line GC/MS. Fuel Process. Technol. 49, 1-15 (1996)

16. Luo, M., Curtis, C.W.: Thermal and catalytic coprocessing of Illinois No. 6 coal with model and commingled waste plastics. Fuel Process. Technol. 49, 91-117 (1996)

17. Ding, W., Liang, J., Anderson, L.L.: Hydrocracking and hydroisomerization of high-density polyethylene and waste plastic over zeolite and silica-alumina-supported $\mathrm{Ni}$ and $\mathrm{Ni}-\mathrm{Mo}$ sulfides. Energy Fuels 11, 1219-1224 (1997)

18. Ding, W., Liang, J., Anderson, L.L.: Thermal and catalytic degradation of high density polyethylene and commingled post-consumer plastic waste. Fuel Process. Technol. 51, 47-62 (1997)

19. Shah, N., Rockwell, J., Huffman, G.P.: Conversion of waste plastic to oil: direct liquefaction versus pyrolysis and hydroprocessing. Energy Fuels 13, 832-838 (1999)

20. Karagöz, S., Yanik, J., Uçar, S., Song, C.: Catalytic coprocessing of low-density polyethylene with VGO using metal supported on activated carbon. Energy Fuels 16, 1301-1308 (2002)

21. Ali, M.F., Nahid, M., Siddiqui, S., Redhwi, H.H.: Study on the conversion of waste plastics/petroleum resid mixtures to transportation fuels. J. Mater. Cycles Waste Manage. 6, 27-34 (2004)

22. Ochoa, R., Van Woert, H., Lee, W., Subramanian, R., Kugler, E., Eklund, P.: Catalytic degradation of medium density polyethylene over silica-alumina supports. Fuel Process. Technol. 49, 119-136 (1996)

23. Akah, A., Hernandez-Martinez, J., Garforth A.: Enhanced feedstock recycling: NovaCrack. In: Proceedings of the 23rd Annual Saudi-Japan symposium. Saudi Arabia (2013)

24. Akah, A., Hernandez-Martinez, J., Rallan, C., Garforth, A.A.: Enhanced feedstock recycling of post-consumer plastic waste. Chem. Eng. Trans. 43, 2395-2400 (2015)

25. Munir, D., Usman, M.R.: Catalytic hydropyrolysis of a model municipal waste plastic mixture over composite USY/SBA-16 catalysts. J. Anal. Appl. Pyrolysis 13, 44-53 (2018)
26. Serrano, D., Aguado J., Escola J., Garagorri E., Rodríguez J., Morselli L., Palazzi, G., Orsi, R.: Feedstock recycling of agriculture plastic film wastes by catalytic cracking. Appl. Catal. B: Environ. 49, 257-265 (2004)

27. Syamsiro, M., Saptoadi, H., Norsujianto, T., Noviasri, P., Cheng, S., Alimuddin, Z.: Fuel oil production from municipal plastic wastes in sequential pyrolysis and catalytic reforming reactors. Energy Proc. 47, 80-188 (2014)

28. Munir, D., Piepenbreier, F., Usman, M.R.: Hydrocracking of a plastic mixture over various micro-mesoporous composite zeolites. Powder Technol. 316, 542-550 (2017)

29. Munir, D., Usman, M.R.: Synthesis and characterization of mesoporous hydrocracking catalysts. IOP Conf. Series Mater. Sci. Eng. 146, 1-7 (2016)

30. Aguado, J., Serrano, D.P., Romero, M.D., Escola, J.M.: Catalytic conversion of polyethylene into fuels over mesoporous MCM-41. Chem. Commun. 1, 725-726 (1996)

31. Aguado, J., Sotelo, J.L., Serrano, D.P., Calles, J.A., Escola, J.M.: Catalytic conversion of polyolefins into liquid fuels over MCM-41: Comparison with ZSM-5 and amorphous $\mathrm{SiO}_{2}-\mathrm{Al}_{2} \mathrm{O}_{3}$. Energy Fuels 11, 1225-1231 (1997)

32. Bonetto, L., Camblor, M.A., Corma, A., Perez-Pariente, J.: Optimization of zeolite- $\beta$ in cracking catalysts influence of crystallite size. Appl. Catal. A: Gen. 82, 37-50 (1992)

33. Kiricsi, I., Flego, C., Pazzuconi, G., Parker, W.J., Millini, R., Perego, C., Bellussi, G.: Progress toward understanding zeolite beta acidity: an IR and 27Al NMR spectroscopic study. J. Phys. Chem. 98, 4627-4634 (1994)

34. Munir, D.: Catalytic hydrocracking of waste plastics to liquids. PhD Thesis, University of the Punjab, Lahore (2018)

35. Guo, W., Huang, L., Deng, P., Xue, Z., Li, Q.: Characterization of Beta/MCM-41 composite molecular sieve compared with the mechanical mixture. Microporous Mesoporous Mater. 44-45, 427-434 (2001)

36. Zhang, D., Duan, A., Zhao, Z., Wang, X., Jiang, G., Liu, J., Wang, C., Jin, M.: Synthesis, characterization and catalytic performance of meso-microporous material Beta-SBA-15-supported NiMo catalysts for hydrodesulfurization of dibenzothiophene. Catal. Today 175, 477-484 (2011)

37. Jia, L., Sun, X., Ye, X., Zou, C., Gu, H., Huang, Y., Niu, G., Zhao, D.: Core-shell composites of USY @ Mesosilica: synthesis and application in cracking heavy molecules with high liquid yield. Microporous Mesoporous Mater. 176, 16-24 (2013)

38. Cao, Z., Zhang, X., Xu, C., Duan, A., Guo, R., Zhao, Z., Wu, Z., Chong, P., Li, J., Wang, X., Meng, Q.: The synthesis of Al-SBA-16 materials with a novel method and their catalytic application on hydrogenation for FCC diesel. Energy Fuels 31, 805-814 (2016)

39. Ma, Y., Hu, J., Jia, L., Li, Z., Kan, Q., Wu, S.: Synthesis, characterization and catalytic activity of a novel mesoporous ZSM-5 zeolite. Mater. Res. Bull. 48, 1881-1844 (2013)

40. Mouli, K.C., Soni, K., Dalai, A., Adjaye, J.: Effect of pore diameter of Ni-Mo/Al-SBA-15 catalysts on the hydrotreating of heavy gas oil. Appl. Catal. A: Gen. 404, 21-29 (2011)

41. Sun, H., Tang, Q., Du, Y., Liu, X., Chen, Y., Yang, Y.: Mesostructured SBA-16 with excellent hydrothermal, thermal and mechanical stabilities: Modified synthesis and its catalytic application. J. Colloid Interf. Sci. 333, 317-323 (2009)

42. Shah, T., Lia, B., Abdalla, Z.E.A.: Direct synthesis of Ti-containing SBA-16-type mesoporous material by the evaporationinduced self-assembly method and its catalytic performance for oxidative desulfurization. J Colloid Interf Sci. 336, 707-711 (2009) 
43. Parry, E.P.: An infrared study of pyridine adsorbed on acidic solids: characterization of surface acidity. J Catal. 2, 371-379 (1963)

44. Chakraborty, B., Viswanathan, B.: Surface acidity of MCM-41 by in situ IR studies of pyridine adsorption. Catal. Today 49, 253-260 (1999)

45. Akbaş, A., Mitzel, H., Hönice, D.: Investigation of acid sites on $\mathrm{V}_{2} \mathrm{O}_{5} / \mathrm{TiO}_{2}(\mathrm{~A})$ catalysts by FTIR with adsorption of pyridine. Turk. J. Chem. 20, 38-42 (1996)

46. Li, X., Li, B., Xu, J., Wang, Q., Pang, X., Gao, X., Zhou, Z., Piao, J.: Synthesis and characterization of Ln-ZSM-5/MCM-41 $(\mathrm{Ln}=\mathrm{La}, \mathrm{Ce})$ by using kaolin as raw material. Appl. Clay Sci. 50, 81-86 (2010)

47. Taghavimoghaddam, J., Knowles, G.P., Chaffee, A.L.: Impact of preparation methods on SBA-15 supported low cobalt-content composites: structure and catalytic activity. J. Mol. Catal. A: Chem. 377, 115-122 (2013)

48. Xia, Y., Mokaya, R.: On the synthesis and characterization of ZSM-5/MCM-48 aluminosilicate composite materials. J. Mater. Chem. 14, 863-870 (2004)

49. Williams, P.T., Slaney, E.: Analysis of products from the pyrolysis and liquefaction of single plastics and waste plastic mixtures. Resour. Conserv. Recy. 51, 754-769 (2007)

Publisher's Note Springer Nature remains neutral with regard to jurisdictional claims in published maps and institutional affiliations. 